\title{
EVASÃO E PERMANÊNCIA NO CURSO DE PEDAGOGIA EAD DA UFRN: UM CONVITE À REFLEX̃̃O
}

\author{
Evasion and permanence in the UFRN EaD Pedagogy course: an invitation to \\ reflection
}

\author{
Evasión y permanencia en el curso de Pedagogía de UFRN EaD: una invitación a la \\ reflexión
}

Andréia da Silva Quintanilha Sousa*

Júlio Ribeiro Soares ${ }^{* *}$

\begin{abstract}
Resumo
O artigo discute a permanência e a evasão no curso de Pedagogia ofertado na modalidade a distância pela Universidade Federal do Rio Grande do Norte, com foco nos dados das três turmas constituídas desde o início do curso, isto é, 2012, quando ingressaram 584 estudantes; 2014, com o ingresso de 297; e 2017, com 168 estudantes. A taxa de evasão nessas turmas, até o fim de 2019, era em torno de $38 \%, 40 \%$ e $20 \%$, respectivamente. Sendo um trabalho que se pretende reflexivo, alguns atores foram convidados a falar sobre a questão abordada. Para fundamentar a discussão, o estudo busca apoio no debate acerca das políticas públicas dentro da abordagem cognitivista em que o referencial global/setorial sustenta as análises das políticas para a formação de professores. Com isso, aponta que parece haver um certo consenso entre os estudiosos das políticas educacionais de que existe articulação entre educação/escolarização e a forma social de organização da existência humana. As mudanças no comportamento das forças produtivas capitalistas no mundo, como reconhecem os estudiosos, atingem a vida contemporânea em diversos setores. Nessa perspectiva, a formação de professores para atuar na educação básica não estaria isenta das novas exigências que envolvem a sociedade marcada pela racionalidade neoliberal.
\end{abstract}

PALAVRAS-CHAVE: Racionalidade neoliberal. Formação de professores. Educação à Distância.

\begin{abstract}
The article discusses the permanence and dropout in the Pedagogy course offered in the distance modality by the Federal University of Rio Grande do Norte, focusing on the data of the three classes constituted since the beginning of the course, that is, 2012, when 584 students joined; 2014, with the entry of 297; and 2017, with 168 students. The dropout rate in these classes, until the end of 2019 , was around $38 \%, 40 \%$ and $20 \%$, respectively. As a work that is intended to be reflective, some actors were invited to talk about the issue addressed. To support the discussion, the study seeks support in the debate about public policies within the cognitive approach in which the global / sectorial framework supports the analysis of policies for teacher education. Thus, it points out that there seems to be a certain consensus among scholars of educational policies that there is an articulation between education / schooling and the social form of organization of human existence. The changes in the behavior of capitalist productive forces in the world, as scholars recognize, affect contemporary life in several sectors. In this perspective, the training of teachers to work in

\footnotetext{
*Doutora em Educação. Docente vinculada à Universidade Federal do Rio Grande do Norte (UFRN). E-mail: andreia_quintanilha_sousa@ hotmail.com. Oricid: https://orcid.org/0000-0002-4540-4020

*** Doutor em Educação. Docente vinculada à Universidade Federal do Rio Grande do Norte (UFRN). E-mail: julioribeirosoares@yahoo.com.br. Orcid: https://orcid.org/0000-0002-3288-7756
} 
basic education would not be exempt from the new requirements that involve society marked by neoliberal rationality.

KEYWORDS: Neoliberal rationality. Teacher training. Distance Education.

\section{Resumen}

El artículo analiza la permanencia y el abandono del curso de pedagogía ofrecido en la modalidad a distancia por la Universidad Federal de Rio Grande do Norte, centrándose en los datos de las tres clases constituidas desde el comienzo del curso, es decir, 2012, cuando se unieron 584 estudiantes; 2014, con la entrada de 297; y 2017, con 168 estudiantes. La tasa de deserción en estas clases, hasta finales de 2019, fue de alrededor del $38 \%, 40 \%$ y $20 \%$, respectivamente. Como un trabajo que pretende ser reflexivo, algunos actores fueron invitados a hablar sobre el tema abordado. Para apoyar la discusión, el estudio busca apoyo en el debate sobre políticas públicas dentro del enfoque cognitivo en el que el marco global / sectorial apoya el análisis de políticas para la educación docente. Por lo tanto, señala que parece haber cierto consenso entre los estudiosos de las políticas educativas de que existe una articulación entre la educación / escolaridad y la forma social de organización de la existencia humana. Los cambios en el comportamiento de las fuerzas productivas capitalistas en el mundo, como reconocen los académicos, afectan la vida contemporánea en varios sectores. En esta perspectiva, la capacitación de docentes para trabajar en educación básica no estaría exenta de los nuevos requisitos que involucran a la sociedad marcada por la racionalidad neoliberal.

PALABRAS CLAVE: Racionalidad neoliberal. Formación de professores. Educación a Distancia.

\section{INTRODUÇÃO}

Neste artigo discutimos a permanência e a evasão no Curso de Pedagogia na modalidade a distância tomando como ponto de partida o debate acerca das políticas públicas para a formação de professores nessa modalidade no contexto da racionalidade neoliberal em interlocução com os depoimentos coletados.

Optar pela análise de políticas públicas numa abordagem cognitiva significa ter em mente que "a ação pública" compreende problemas que são muitas vezes "multiformes" e de "origens variáveis", conforme aponta Muller (2018, p. 114). Em outras palavras, se de um lado estudar a ação pública (política para a formação de professores) não pode escapar da "setorização" (Programa UAB/UFRN), de outro, não é possível desconsiderar a "natureza global do problema" (formação a distância dentro dos marcos da racionalidade neoliberal) (MULLER, 2018) bem como a dimensão cognitiva dos atores.

No caso do Programa Universidade Aberta do Brasil, temos diferentes atores envolvidos na sua implementação: os governantes, os prefeitos e gestores dos entes federados, as secretarias de Educação dos estados e municípios, os sindicatos dos trabalhadores da educação básica e da superior, os técnicos e gestores das Instituições de educação superior pública, as empresas fornecedoras de infraestruturas necessárias à modalidade a distância, bolsistas, tutores, agências de fomento e os docentes.

A adesão das instituições públicas em parceria com entes federados ao Programa $\mathrm{UAB}$, visando à formação de professores em serviço na modalidade a distância, trouxe no seu bojo muita contradição e conflitos. 
Assim, na primeira parte deste trabalho discutimos o ponto de partida das nossas análises da política pública, compreendendo que política pública não é um dado, mas uma "construção social".

No segundo momento, apresentamos o histórico de criação e os índices do Curso de Pedagogia UAB/UFRN. Também transcrevemos e refletirmos sobre o teor de alguns depoimentos coletados.

E por fim, nas considerações finais, temos como norte que a análise das políticas públicas, numa abordagem cognitivista, não é um dado, mas uma construção social e que a evasão merece avaliação e monitoramento por ser um problema multidimensional.

\section{Decodificando as lógicas que operam na elaboração da política de formação de professores à distância}

A política pública não é algo simples de se analisar, pois uma política é constituída por um conjunto de medidas concretas, "não é um processo abstrato de decisão do qual podemos apreender 'do exterior' o sentido. É, conforme Muller (2018, p. 33), “indispensável 'abrir a caixa preta' e identificar os atores que participam da policy making para analisar suas estratégias e entender as causas de seus comportamentos".

Assim, o objetivo das políticas públicas é gerenciar os desequilíbrios provenientes da setorização e, por consequência, da complexidade da sociedade moderna, resultado da divisão do trabalho, pois os diferentes conjuntos setoriais e a multiplicidade de mediações colocam no "centro do palco" uma nova categoria de atores cuja legitimidade está baseada em uma profissão ou em um grupo de interesse focalizado em um determinado setor da "ação pública".

Trata-se de uma sociedade setorial em permanente desequilíbrio cujos problemas devem constituir objetos de políticas públicas. No caso do setor educacional brasileiro, os problemas devem estar presentes na agenda do poder público e culminar na elaboração e formulação de alternativas e eventuais soluções. No tocante à formação de professores da educação básica, uma das "soluções" para garantir o acesso dos professores à educação superior foi a criação, pelo Decreto n. 5.800, de junho de 2006, do Sistema Universidade Aberta do Brasil - UAB.

De fato, as políticas de formação de professores nas últimas décadas “[...] denotam que a formação de professores foi operacionalizada através da modalidade a distância”, como afirma Sousa (2015, p. 103). Esse projeto oficial mantém coerência com a agenda dos organismos internacionais que defendem um modelo de formação de profissionais da educação por meio da modalidade a distância.

Dentre os documentos apresentados por Sousa (2015), destacamos aqui o PNE (PNE 2001-2010) sancionado pela Lei ${ }^{\circ}$ 10.172/2002 e o Plano Nacional de Educação (PNE 2014-2024) sancionado pela Lei $\mathrm{n}^{\mathrm{o}}$ 13.003/2014.

No primeiro PNE (2001-2010), é possível ler que o Poder Público “tem dado prioridade à atualização e aperfeiçoamento de professores para o ensino fundamental e ao enriquecimento do instrumental pedagógico disponível para esse nível de ensino" por meio do incentivo e desenvolvimento de programas de educação a distância, em todos os níveis e modalidades.

Também o PNE (2014-2024) apresenta como estratégia para elevar a taxa bruta de matrículas na educação superior para 50\% e "[...] para 33\% a taxa líquida da ampliação de ofertas de vagas por meio da expansão e interiorização da Rede Federal de Educação 
Superior, da Rede Federal de Educação Profissional e do Sistema Universidade Aberta do Brasil".

Como podemos constatar nos documentos oficiais, a Universidade Aberta do Brasil representa uma estratégia para a expansão da educação superior pública no sentido de ampliar o acesso de professores da educação básica a esse nível educacional. Noutras palavras, conforme pontuado por Silva Júnior e Martins (2016, p. 39), o referido Programa, criado no processo de estruturação da educação superior ocorrida na última década, "se justifica no direito de cidadania e no retorno ou contemplação de parcelas da população geograficamente excluídas do acesso ao ensino superior, assumindo-se como forma de promoção do desenvolvimento socioeconômico das diversas regiões do Brasil".

No contexto marcado pela racionalidade neoliberal, formar professores é um problema político que está na "agenda dos decisores". O problema político é uma "construção social" cuja configuração depende de múltiplos fatores, vontades, valores, normas e concepções.

Nesse sentido, formar professores implica definir saberes, competências técnicas, pedagógicas, políticas e socioculturais que devem estar presentes na construção de uma sociedade. E quais são as concepções de educação presentes na sociedade atual, marcada pela racionalidade neoliberal?

Concordamos com Dardot e Laval (2016, p. 20-22) quando defendem que o neoliberalismo emprega técnicas de poder inéditas sobre as condutas e as subjetividades". De fato, a racionalidade neoliberal não se deve "apenas à crise do capitalismo nem surgiu de repente. Ela foi "precedida e acompanhada de uma luta ideológica [...] contra o Estado de bem-estar", conforme Dardot e Laval (2016, p. 193).

Em outras palavras, essa ofensiva alimentou a ação de certos governos e contribuiu para a legitimação da "nova norma", no entanto, "apenas a conversão dos espíritos não teria sido suficiente, foi necessária uma mudança de comportamento [...], obra, em grande parte, de técnicas e dispositivos de disciplina".

Os teóricos identificam no neoliberalismo mais do que uma ideologia ou um tipo de política econômica, mas uma racionalidade que afeta as condutas, os discursos e as práticas na sociedade, que, "[...] embora seja inegavelmente uma sociedade capitalista, essa sociedade diz respeito a uma figura singular do capitalismo que exige ser analisada como tal em sua irredutível especificidade" (DARDOT; LAVAL, 2016, p. 26). Para esses autores, "[...] estamos lidando não com uma, mercantilização sorrateira", mas com uma expansão da racionalidade de mercado a toda a existência por meio da generalização da forma-empresa" (DARDOT; LAVAL, 2016, p. 27).

É indiscutível que a "generalização da forma-empresa" pode ser observada na medida em que é cobrada uma permanente capacitação e essa "busca constante por capacitação contribui sobremaneira para a abertura de instituições de ensino em todos os níveis", especialmente pela via da educação a distância, como bem apontam Maia e Bernardes (2019, p. 34).

Nesse contexto, a Universidade Aberta do Brasil é apresentada como política pública de formação de professores inicial e continuada capaz de ampliar o contingente de docentes qualificados em nível superior, pois a formação de professores passa a constituir um elemento fundamental para que haja garantia da melhoria do desempenho educacional do país cujo "aumento da produtividade do indivíduo-trabalhador" representa a maximização crescente de seus rendimentos ao longo da vida (MAIA; BERNARDES, 2019, p. 34). 
De fato, na última década, o crescimento dos cursos foi da ordem de mais de $2.000 \%$ e das matrículas o percentual de crescimento foi na casa dos $3.000 \%$, conforme Sousa e Maciel (2016). Contudo, as pesquisas têm evidenciado altas taxas de evasão/abandono que merecem atenção (SOUSA; SOUSA, 2016; SOUSA; MACIEL, 2016).

Em consonância com a expansão de matrículas, a evasão também apresenta aumento importante e que merece atenção, uma vez que a ampliação do acesso vem acompanhada pela ampliação dos percentuais de evasão na educação superior pública.

\section{A evasão e a permanência no curso de Pedagogia EAD: questões para reflexões}

De acordo com o Projeto Pedagógico do Curso de Pedagogia - modalidade a distância, da Universidade Federal do Rio Grande do Norte (UFRN, 2019), a proposta de implantação do referido curso foi apresentada entre 2009/2010, tendo como justificativa um conjunto de demandas apresentadas por municípios potiguares, _sobre a necessidade e a importância da formação de docentes, em nível superior.

A criação do Curso de Pedagogia EaD/UFRN atende, portanto, a uma demanda educacional muito ampla, com caráter político e social.

O primeiro edital de seleção de candidatos para o Curso de Pedagogia na modalidade a distância, ofertada pela UFRN, ocorreu no ano de 2012. De acordo com dados do Sistema Integrado de Gestão de Atividades Acadêmicas (SIGAA), nesse período ingressaram 401 candidatos, pela via do vestibular, e 183 pelo Programa Nacional de Formação de Professores da Educação Básica (Parfor), totalizando o ingresso de 584 candidatos, com vagas distribuídas entre os polos de Caicó, Caraúbas, Currais Novos, Grossos, Luís Gomes, Macau, Marcelino Vieira, Martins, Natal, Nova Cruz e Parnamirim. Desse total, 356 alunos concluíram os estudos, 225 cancelaram suas matrículas e 2 ainda permanecem ativos no curso.

Em 2014, o Curso de Pedagogia foi contemplado com 297 vagas, distribuídas entre os polos de Caicó, Caraúbas, Currais Novos, Macau, Parnamirim e São Gonçalo do Amarante.

A terceira entrada no curso Pedagogia EaD/UFRN ocorreu em 2017.2, com a oferta de 168 vagas distribuídas entres os polos de Currais Novos, Lajes, Marcelino Vieira e Nova Cruz.

Passados dez anos da sua criação, e três processos seletivos ocorridos nos anos de 2012, 2014 e 2017, o Curso de Licenciatura em Pedagogia, na modalidade EaD, ainda não conta com oferta regular. E mesmo que o Projeto Pedagógico do Curso tenha sido reformulado e aprovado no final do ano de 2019, o curso não conta, até o momento, com a perspectiva concreta de uma nova entrada de candidatos.

Com relação ao total de ingressantes, ativos, concluídos e cancelados no Curso de Pedagogia UAB/UFRN temos os seguintes percentuais: dos 584 ingressantes no ano de 2012.2, 227 cancelaram suas matrículas $(38,86 \%)$ e $356(61,13 \%)$ concluíram. Os ingressantes em 2014.1 foram um total de 297, cancelaram $119(40,06 \%)$ e $164(55,21 \%)$ concluídos, ainda temos 14 alunos ativos em 2019.2. Os ingressantes de 2017.2 foram 168, 133 estão ativos e 35 cancelaram suas matrículas (20,83\%). Nas três entradas foram 1.049 ingressantes e até o final do ano de 2019381 alunos cancelaram suas matrículas conforme dados coletados no Sistema Integrado de Gestão de Atividades (SIGAA, 2019).

Os percentuais de matrículas canceladas, em especial aqueles correspondentes às turmas 2012.2 e 2014.1, por serem turmas nas quais os alunos já atingiram o tempo 
mínimo para colação de grau, denota que a evasão no Curso de Pedagogia EAD/UFRN é um problema a ser enfrentado, na perspectiva de que, além do acesso ao ensino superior, é necessário que políticas e ações pedagógicas sejam desenvolvidas com a finalidade de garantir a permanência do estudante na universidade.

O fenômeno da evasão estudantil é um problema que extrapola a realidade brasileira. Trata-se de um problema internacional, que tem mobilizado pesquisadores como Tinto (2007); Polydoro et al. (2001); Aretio (2002); Fior, Mercuri e Almeida (2011); Ambiel (2015); Sousa e Souza (2016) e Sousa e Maciel (2016), objetivando compreender as motivações que são preditivas à evasão.

Os motivos que levam o estudante à decisão de se desligar de seu curso superior em caráter temporário ou definitivo não podem ser justificados somente por um componente; as pesquisas na área indicam que um conjunto de fatores interferem na permanência, ou não, do estudante na educação superior. Segundo Nunes e Veloso (2016, p. 51), "discutir sobre a permanência do estudante na universidade deve consistir em identificar dificuldades que influenciam na desistência precoce, ou tempo maior no curso, às vezes inviabilizando a sua conclusão".

Assim, apontando que o ambiente acadêmico e a satisfação na escolha do curso, entre outros elementos, interferem na permanência do estudante na universidade, Nunes e Veloso (2016, p. 51) ressaltam que o apoio necessário ao estudante "para ter sucesso no seu percurso acadêmico deve ser definido mediante políticas de permanência e projetos institucionais, para que o acesso à educação superior seja garantido".

De acordo com Ambiel (2015), Souza, Mártires e Souza (2018), os elementos componentes que determinam a evasão em geral podem estar relacionados a motivos institucionais (qualidade do corpo docente, serviços de infraestrutura); motivos pessoais e vocacionais (dúvida em relação à escolha da profissão, se tem vocação, problemas de saúde); motivos relacionados à falta de suporte (dificuldades de ordem financeira, conciliar estudos e trabalho, conflito entre carga horária de trabalho e as exigências do curso, restando pouco tempo para realizar as atividades), motivos relacionados à carreira (o salário e o mercado); motivos vinculados ao desempenho acadêmico (baixo desempenho nas disciplinas); motivos interpessoais (dificuldades para se relacionar com colegas, professores e gestores); motivos referentes à autonomia (assumir responsabilidade de morar sozinho). ( AMBIEL,2015;SOUSA,MÁRTIRES,SOUSA,2018).

De fato, elevados índices de evasão não são uma realidade exclusiva do Curso de Pedagogia a distância da Universidade Federal do Rio Grande do Norte, nem dos demais cursos superiores de educação a distância dessa Universidade. É uma realidade que também constitui os cursos superiores de educação a distância e presenciais oferecidos por outras instituições universitárias do país. Estudo da Associação Brasileira de Educação a Distância (ABED) sobre o ano de 2018 revela que 22,2\% das instituições que ofertam essa modalidade de ensino apresentaram "taxas de evasão entre 26\% e 50\%" (ABED, 2019, p. 66). Com os índices de evasão no Curso de Pedagogia EAD/UFRN variando entre 38,86\% e $40,06 \%$, é possível que a instituição também esteja nesse patamar dos $22,2 \%$ das instituições brasileiras.

Interessa-nos primordialmente saber: quais foram os motivos que levaram os discentes ingressantes no ano de 2014.1 a abandonarem o curso? A elevada taxa de evasão $(42,09 \%)$ foi ocasionada por quais fatores?

O coordenador atual do curso (Entrevistado 1) aponta que, para enfrentamento do problema da evasão, é necessário que o curso não se distancie dos alunos, especialmente daquilo que se constitui como motivo maior para que permaneçam no curso, isto é, o 
interesse pela aprendizagem. Por isso, segundo o coordenador do curso (Entrevistado 1), "é preciso que esteja mais próximo do aluno, com as atividades da disciplina, atividades de extensão, realizando encontros". O coordenador é enfático em dizer que não consegue "enxergar outra forma da gente fixar o aluno no curso se não for se aproximando dele com as atividades que a gente tem que fazer" (Entrevistado 1).

Esse pensamento do coordenador se remete a uma questão crucial do cotidiano da educação escolar, distanciando-se de qualquer visão simplista, uma vez que encontra fundamento científico em estudos sobre o assunto, tal como em Tassoni (2011, p. 58), quando aponta que "as experiências de sucesso vividas nas situações de aprendizagem em sala de aula podem contribuir para a permanência dos alunos na escola".

Mas a evasão, ainda segundo o Entrevistado 1 não é um problema apenas pedagógico, uma vez que pode estar relacionado a questões pessoais. Assim, citando casos reais vividos na atividade docente, o coordenador chama atenção para o fato de que a evasão também acontece, por exemplo, quando "o aluno teve um problema sério na família", "ficou muito doente", "teve uma morte na família" ou mesmo porque "entrou em depressão". Mas o coordenador vai além da descrição dos casos que podem se constituir como motivo de evasão e aponta possibilidades de intervenção, inclusive relacionadas à instituição educacional. Ele ressalta que "a proximidade de alguém para dar um apoio presencial é o que mais ajuda". E no caso específico do Curso de Pedagogia UAB/UFRN, aponta que "o tutor presencial [que atua no polo] pode dar uma ajuda... ele pode ser essa figura de apoio à aprendizagem quando existe essa possibilidade". Corroborando a ideia do coordenador, é pela proximidade com o outro, cuja relação é marcada pela colaboração, que se constitui a nossa possibilidade de desenvolvimento.

Quando perguntamos a um dos ex-tutores do Curso de Pedagogia UAB/UFRN a distância (Entrevistado 3) qual a sua percepção com relação à evasão no curso, ele, que trabalhou como tutor a distância "por cerca de cinco anos" e considera o "curso muito bem organizado", a sua percepção é a de que "a evasão ocorre pelos motivos mais diversos. Às vezes por questões pessoais, que fogem, no meu entender, do esforço institucional para garantir a permanência do estudante. Por exemplo, se de repente a pessoa descobre que não possui afinidade com o curso ou muda o projeto de vida, mudando de cidade, ou coisas desse tipo".

Para o Entrevistado 3 "[...] não há muito o que a instituição possa fazer. Ninguém pode obrigar o estudante a ficar. Contudo, há os que se evadem pela ausência de uma formação mais sólida na educação básica. [...]" Aponta também aspectos vocacionais e ainda " o espírito do capitalismo, ingressa num curso de graduação por enxergar o fenômeno educativo como economicamente estratégico"

O Entrevistado 3 reconhece que alguns procuram a modalidade a distância pelas "[...] vantagens em conciliar com outras atividades, [...] pensando apenas na certificação [...] não necessariamente por objetivarem a aprendizagem dos conteúdos (o que demandaria muita disciplina de estudos), mas sim dão maior relevância à obtenção do título, que certificará o status de empregabilidade".

O ex-tutor entende que a motivação meramente pela certificação pode fazer com que os estudantes se evadam diante de maiores exigências de leituras e atividades. Enfim, ao se discutir esse assunto, não acho que a redução na exigência dos conteúdos e das avaliações seja o caminho mais correto. As pessoas precisam entender que fazer um curso de graduação efetivamente exige bastante esforço. Por outro lado, docentes e tutores precisam estar permanentemente melhorando suas práticas pedagógicas a fim de que os estudantes se sintam motivados e interessados no curso (Entrevistado 3). 
Como podemos depreender dos depoimentos, tendo como base o que Laval e Dardot chamam de "racionalidade neoliberal", as aspirações e as novas condutas dos sujeitos, no contexto atual, produzem um sujeito que necessita se conduzir como uma "entidade em competição", em busca pela "obtenção do título, que certificará o status de empregabilidade", como o Entrevistado 3 (ex-tutor) afirmou acima.

Assim, essa "modelagem da sociedade pela empresa" cria as novas condutas dos sujeitos, cuja influência modelam comportamentos "[...] expondo-os a riscos e assumindo inteira responsabilidade por eventuais fracassos", como apontam Dardot e Laval (2016, p. 328).

Em outras palavras, a busca por certificação visando a tão falada "empregabilidade" numa sociedade marcada pelo desemprego estrutural parece ser uma forma de "jogar na conta" apenas do indivíduo o sucesso acadêmico e profissional. Por isso, são importantes os estudos sobre os fatores preditivos à evasão para que todo o sucesso acadêmico não seja focado na dimensão pessoal do aluno, tendo em vista que se trata de um fenômeno multidimensional.

Nesse passo, tanto a dimensão pessoal, institucional e social quanto a dimensão profissional não deve ser negligenciada quando estudamos o tema evasão e permanência na educação superior.

O depoimento de um professor do Curso de Pedagogia UAB/UFRN aponta nesse sentido, como se pode depreender do seu relato quando aponta a evasão como "um problema que está para além do aluno". E reconhece que não se trata apenas de um problema do indivíduo ou como a instituição lida com o processo pedagógico, pois para esse professor a evasão "[...] é algo mais complexo. Se você observar bem, a evasão é um problema social, um problema que tem a ver com a exclusão social, com a desigualdade. Tem a ver com a forma de existência das pessoas nesse mundo[...]

Para esse mesmo professor, "questões pedagógicas estão relacionadas, mas penso que não são elementos determinantes. $\mathrm{O}$ aluno que desiste do seu curso superior é um aluno que, acredito, tem outras demandas, talvez mais urgentes do que ter um curso superior". Em outras palavras, para ele, “[...] tanto a evasão quanto a permanência do aluno no seu curso superior são uma questão que deve ser estudada a luz da sua totalidade, considerando as múltiplas relações sociais e pedagógicas possíveis". Reconhecendo que "[...] cada caso tem a sua singularidade.

Com relação a modalidade a distância, afirma que [...] é uma maneira de democratizar o acesso de algumas pessoas ao ensino superior". Entretanto, como se trata "de um público muito específico, geralmente que trabalha o dia inteiro, e que muitas vezes são pessoas responsáveis por atribuições dentro da família e da comunidade onde vivem, além de viverem, aliás, vivermos numa sociedade excludente". Em outras palavras, ele acredita "que evasão na educação a distância seja um problema mais recorrente do que na educação presencial". E finaliza, "o grande problema mesmo acredito que seja a sua naturalização, ou seja, o grande problema da evasão não é a evasão em si mesma, porque ela é um reflexo de um fenômeno social que leva o indivíduo a não ter mais tempo e interesse para continuar (Entrevistado 2).

O depoimento do professor ratifica que o fenômeno da evasão é um fenômeno multidimensional em que a condição designada como resiliência precisa ser levada em conta.

Nesta pesquisa também consideramos importante trazer a reflexão do corpo discente do curso, aqui "representado", de alguma forma, por uma aluna já graduada pelo Curso de Pedagogia UAB/UFRN. As reflexões da Entrevistada 4 sobre evasão e 
permanência parecem não divergir das reflexões desenvolvidas por outros atores que também colaboraram com este nosso estudo, mas a sua fala se destaca pelo "lugar" de onde ela pensa. Entre outras questões, é uma fala que se destaca pela expressão de temas relacionados ao papel do compromisso acadêmico e do desenvolvimento da autonomia dos alunos em relação aos estudos, o papel pedagógico da instituição no apoio aos alunos, a importância do material didático e, por fim, o diferencial do Curso de Pedagogia na sua formação acadêmica.

Em relação ao papel que, segundo a aluna, deve ser assumido pelos demais alunos como compromisso acadêmico, tendo em vista o desenvolvimento de sua autonomia em relação aos estudos, ela ressalta que "o modelo de educação a distância exige, por parte do aluno, maior autonomia e autodidatismo. Ou seja, o estudante precisa se organizar, ter disciplina, desenvolver uma rotina de estudos".

Aponta, portanto, para a necessidade de o aluno atuar como sujeito do processo de aprendizagem, de modo que, para cumprir seus compromissos acadêmicos, é preciso desenvolver hábitos, novas formas de comportamento, como, segundo a própria aluna, organização, disciplina e rotina de estudo. Ao mesmo tempo, é importante ressaltar que ela não secundariza ou descarta "o papel pedagógico da instituição no apoio aos alunos", considerado crucial para que o aluno possa avançar na vida acadêmica. Conforme ela mesma pontua, tais "[...]características [organização, disciplina e rotina de estudo], porém, não significam que a instituição não precisa acompanhar pedagogicamente o discente, mesmo que por meio do ambiente virtual. É importante que se estreitem as relações entre coordenação, corpo docente, tutores e estudantes (Entrevistada 4).

A sua reflexão sobre o papel do aluno e da instituição parece não divergir das reflexões desenvolvidas pelos demais sujeitos que colaboraram com este estudo, pois a relação aluno-instituição não se revela dicotômica, mas com destaque para o fato de que o enfrentamento ao fantasma da evasão passa, entre outras ações, pela força da ação coletiva, que constrói apoios mútuos. Esse modo de pensar dos sujeitos sobre o enfrentamento à questão da evasão nos faz lembrar Tassoni (2011, p. 59) quando afirma que "é por meio da interação com outros que os sujeitos incorporam os instrumentos culturais". Lembrando também do que afirma Vygotsky (2007): é no outro que está a nossa possibilidade de desenvolvimento.

Mas, além da importância do coletivo, a aluna também dirige sua reflexão para o papel dos instrumentos pedagógicos nas possibilidades de desenvolvimento dos alunos. Nessa questão, embora ressalte pontos positivos, ela é crítica em relação a algumas posturas vivenciadas no curso. Os pontos positivos, segundo ela, foram os materiais complementares, "[...]como textos de referências na área abordada pelo conteúdo da disciplina", o que na sua avaliação "[...] elevava a qualidade do processo de ensinoaprendizagem". E destaca que há “[...] aspectos que precisavam ser melhorados [...] tendo em vista que durante o seu processo formativo no Curso de Pedagogia UAB/UFRN aconteciam "avaliações tradicionais, que privilegiavam a memorização em detrimento da reflexão. Assim, ressalto a necessidade de os professores buscarem novas metodologias e didáticas para o ensino na educação a distância[...]", pois, segundo ela “ [...] muitas vezes, a impressão que fica para o aluno é a de que o próprio professor não acredita na modalidade, nem na real vontade do aluno que escolheu essa modalidade para aprender". Quanto ao material didático, é enfática em afirmar que "[...] precisa ter mais qualidade, ou seja, é preciso que todos os professores abandonem essa ideia de apostilas, que, no geral, fazem uma exposição superficial dos conteúdos [...]” (Entrevistada 4). 
A sua crítica é uma reflexão pertinente sobre a realidade vivida no curso. É uma crítica que visa não apenas ressaltar fragilidades, mas contribuir com possibilidades de transformação. Assim, sua crítica é acompanhada também de um olhar sobre o diferencial do curso, o seu potencial acadêmico.

Para além das minhas críticas e das minhas motivações pessoais, acredito que os recursos humanos e virtuais que o Curso de Pedagogia EaD da UFRN dispõe foram fatores importantes para minha permanência, considerando que fiz parte da primeira turma do curso e que todos os envolvidos (alunos, tutores, servidores, terceirizados e docentes) estavam aprendendo e construindo essa nova realidade (Entrevistada 4).

Com destaque para o fato de que "os recursos humanos e virtuais" do curso foram os fatores mais "importantes para minha permanência", talvez essas sejam as questões sobre as quais devam-se realizar novos estudos sobre o Curso de Pedagogia. A sua fala revela que esses recursos se constituíram como poderosos elementos de motivação para que não elevasse ainda mais a alta taxa de evasão do curso.

Cabe salientar que o Curso de Pedagogia dispõe de uma complexa rede de suporte ao seu funcionamento, especialmente de cunho organizacional, humano e físico, visando a elevar os índices de permanência e o êxito de seus estudantes. De modo específico, dispõe do suporte de todos setores da Secretaria de Educação a Distância (Sedis) e suas equipes multiprofissionais de servidores docentes e técnico-administrativos em educação, destacando-se em especial: Tutoria; Coordenadoria Pedagógica; Educomunicação; Mídias; Coordenadoria de Tecnologia da Informação; Suporte; Desenvolvimento e Suporte; Coordenadoria de Produção de Materiais Didáticos; Revisão; Editoração; Audiovisual; Coordenadoria Administrativa e de Projetos; Materiais Interativos; Legendagem, Audiodescrição e Libras; e Formação Permanente (UFRN, 2010).

Cada polo de apoio presencial dispõe, ainda, de uma coordenação própria e de um laboratório de informática, biblioteca, secretaria acadêmica, laboratórios específicos das áreas e tutores presenciais, com horários disponíveis para atendimento aos alunos.

Por fim, podemos afirmar que a formação de professores na modalidade a distância é objeto de controvérsia. A inserção de um problema na agenda política é o produto do "campo de forças". E cabe a nós, pesquisadores, abrirmos a sua "caixa preta".

\section{CONSIDERAÇÕES FINAIS}

A análise das políticas públicas numa abordagem cognitivista "busca ultrapassar o dilema do determinismo e do voluntarismo", propondo uma análise que combina uma certa forma de "determinismo estrutural" e de "voluntarismo" (as escolhas políticas não são totalmente determinadas pelas suas estruturas), repousando sobre a ideia que uma "política pública opera como um vasto processo de interpretação do mundo", passando a oferecer um "conjunto de relações e de interpretações causais que lhes permitem decodificar, decifrar os acontecimentos com os quais eles são confrontados", mas essas interpretações são dependentes das percepções cognitivas e normativas ligadas a uma determinada situação (MULLER; SUREL, 2002, p. 50).

Essa determinada ação pública (formação de professores na modalidade a distância) entra na agenda porque um conjunto de problemas (para garantir aos professores da Educação Básica formação em nível superior) chamou a atenção de um ou de diversos atores públicos. Por isso, como parte dessa ação pública, também não podemos deixar de 
considerar os desafios pedagógicos e as necessidades de mudanças que constituem os sujeitos participantes desse processo, conforme alerta de Rocha (2013, p. 13) na afirmação: "tomando como base que a EaD no Brasil avançou consideravelmente a partir do Sistema $\mathrm{UAB}$ e em ambiente digital, é preciso considerar que os sujeitos desse processo e de outros formatos de $\mathrm{EaD}$ igualmente importantes têm o olhar construído e balizado pelo modelo educacional presencial".

Assim, quando buscamos compreender uma ação pública dentro da abordagem cognitivista é preciso nos concentrarmos em dois aspectos: "decodificar as lógicas administrativas" (a criação do Programa Universidade Aberta do Brasil) que operam na elaboração das políticas públicas e compreender melhor a "complexidade das redes de atores que participam da ação pública" (docentes, tutores, discentes, gestores, empresas, sindicatos, prefeituras, ministérios, agência de fomento), como orientam os autores com os quais temos trabalhado na tentativa de compreender a política de formação de professores na modalidade a distância dentro de um referencial global/setorial (MULLER E SUREL, 2002, p. 55).

Nesse sentido, a opção de expandir a educação superior por meio da educação a distância no geral e para a formação de professores em particular e suas altas taxas de evasão trouxe inquietações sobre tal escolha política. Dentre as inquietações suscitadas estão o problema da evasão, a permanência e o sucesso acadêmico pós-expansão do acesso. Afinal, o que se tem feito para conter a evasão nas Universidades brasileiras?

No que diz respeito às reflexões acerca do Curso de Pedagogia ofertado pelo Programa Universidade Aberta da UFRN e suas altas taxas de evasão, a impressão que o estudo nos proporciona é que ainda não está na agenda o problema da evasão, pois não identificamos atividades sistemáticas de acompanhamento das razões que levaram à média de cancelamento do curso estar em torno de $40 \%$. Também não identificamos a completa incorporação da modalidade a distância na oferta regular do Curso de Pedagogia, haja vista que o valor aluno/ano caiu drasticamente, inviabilizando, segundo o coordenador atual, a abertura de novas turmas.

O estudo, num prisma cognitivo, não visa apenas a ressaltar fragilidades ou apontar problematizações do fenômeno, mas sim marcar o problema num sentido particular imediatamente identificável pelas diferentes operações e atores envolvidos. Cabe a nós, pesquisadores, a tarefa de trazer o problema à tona.

Finalizamos o estudo compreendendo fundamentalmente que estudar o problema da evasão implica reconhecer que se trata de um fenômeno motivado por um conjunto de fatores que envolvem as relações socioculturais e interpessoais, as IES, os cursos e os estudante, os professores, os gestores, os técnicos e as agências de fomento etc. E, ainda, que é preciso ter mais respeito e consideração para com os estudantes de educação superior da modalidade a distância, por meio das políticas que favoreçam a sua permanência e garantam a qualidade da sua formação, levando em conta sua diversidade e necessidades regionais e específicas, além de atenção especial a indissociabilidade entre ensino, pesquisa e extensão.

\section{REFERÊNCIAS}

AMBIEL, Rodolfo A. M. Construção da Escala de Motivos para Evasão do Ensino Superior. Aval. Psicol., Porto Alegre, v. 14, n. 1, p. 41-52, abr. 2015. Disponível em: $<$ http://pepsic.bvsalud.org/scielo.php?script=sci_arttext\&pid=S1677- 
04712015000100006>. Acesso em: 27 abr. 2015.

ARETIO, García Lorenzo. La educación a distancia: de la teoría a la práctica. Barcelona: Ariel, 2002.

ASSOCIAÇÃO BRASILEIRA DE EDUCAÇÃO A DISTÂNCIA (ABED). Censo $E A D . B R$ : relatório analítico da aprendizagem a distância no Brasil 2018. Tradução Camila Rosa. Curitiba: InterSaberes, 2019. E-book.

BRASIL. Lei $\mathrm{n}^{\mathrm{o}}$ 10.172, de 9 de janeiro de 2001. Aprova o Plano Nacional de Educação e dá outras providências. Diário Oficial [da] República Federativa do Brasil: seção 1, Brasília, DF, p. 1, 10 jan. 2001.

BRASIL. Lei $\mathrm{n}^{\circ}$ 13.005, de 25 de junho de 2014. Aprova o Plano Nacional de Educação - PNE e dá outras providências. Diário Oficial [da] República Federativa do Brasil: seção 1, Brasília, DF, p. 1, 26 jun. 2014.

DARDOT, Pierre; LAVAL, Christian. A nova razão do mundo: ensaio sobre a sociedade neoliberal. São Paulo: Boitempo, 2016.

FIOR, Camila A.; MERCURI, Elizabeth; ALMEIDA, Leandro da S. Escala de interação com pares: construção e evidências de validade para estudantes do ensino superior. PsicoUSF (impr.), Itatiba, v. 16, n. 1, p. 11-21, 2011.

LAVAL, Christian. A escola não é uma empresa: o neoliberalismo em ataque ao ensino público. São Paulo: Boitempo, 2019.

MAIA, Suzanir Fernanda; BERNARDES, Anita Guazzelli. Efeitos e formas de jogo para o acesso e para a permanência na educação superior. In: SOUSA, Andréia da Silva Quintanilha; MACIEL, Carina Elisabeth (org.). Desafios na educação superior: acesso, permanência e inclusão. Curitiba: CRV, 2019.

MULLER, Pierre; SUREL, Yves. A análise das políticas públicas. Pelotas: EDUCAT, 2002.

MULLER, Pierre. As políticas públicas. Rio de Janeiro: Editora da Universidade Federal Fluminense, 2018.

NUNES, Roseli Souza dos Reis; VELOSO, Tereza Christina Mertens Aguiar. A permanência na educação superior: múltiplos olhares. Dourados, Educação e Fronteiras On-Line, Dourados-MS, v. 6, n. 6, 2016, p.48 - 63, Disponível em:

http://ojs.ufgd.edu.br/index.php/educacao/article/view/5708

OBSERVATÓRIO DO PLANO NACIONAL DE EDUCAÇÃO (OPNE). Monte seu dossiê. Disponível em: <https://www.observatoriodopne.org.br/dossie> Acesso em: 21 jun. 2018. 
POLYDORO, Soely A. J. et al. Desenvolvimento de uma Escala de Integração ao Ensino Superior. Psico-USF (impr.), Itatiba, v. 6, n. 1, p. 11-17, jun. 2001.

ROCHA, Elizabeth Matos. Saberes e práticas pedagógicas que influenciam na construção da identidade do professor virtual. Dourados, Educação e Fronteiras On-Line, DouradosMS, v. 3, n. 8, 2013, p. 06-21. Disponível em:

http://ojs.ufgd.edu.br/index.php/educacao/issue/view/126/showToc

SILVA JUNIOR, João dos Reis da; MARTINS, Tania Barbosa. Mediações e contradições na educação a distância: o trabalho do professor e do tutor. Dourados, Educação $e$ Fronteiras On-Line, Dourados-MS, v. 6, n. 16, 2016, p. 37 - 47. Disponível em:

http://ojs.ufgd.edu.br/index.php/educacao/article/view/5706

SOUSA, Andréia da Silva Quintanilha. A política de formação de professores das últimas duas décadas: rupturas e continuidades. In: MAUÉS, Olgaíses Cabral; SOUZA, José dos Santos; SEGENREICH, Stella Cecília Duarte (org.). Expansão da Educação Superior: formação e trabalho docente. Belo Horizonte: Fino Traço, 2015.

SOUSA, Andréia da Silva Quintanilha; SILVEIRA, Márcia Cambuí Rosado. Formação de professores de Pedagogia na modalidade a distância face à inclusão. In: SOUSA, Andréia da Silva Quintanilha; MACIEL, Carina Elisabeth (org.). Desafios na Educação Superior: acesso, permanência e inclusão. Curitiba: CRV, 2019.

SOUSA, Andréia da Silva Quintanilha. Universidade Aberta do Brasil (UAB) como política de formação de professores. Revista Educação em Questão, v. 42, n. 28, p. 119148, jan./abr. 2012.

SOUSA, Andréia da Silva Quintanilha. A Evasão no Programa Universidade Aberta do Brasil/UFRN sob a perspectiva da avaliação construtivista. In: SOUZA, Lincoln Moraes; SOUSA, Andréia da Silva Quintanilha (org.). Avaliação de políticas públicas e a avaliação da educação. Curitiba: CRV, 2017.

SOUSA, Andréia da Silva Quintanilha; MACIEL, Carina Elizabeth. Expansão da educação superior: permanência e evasão em cursos da Universidade Aberta do Brasil. Educação em Revista (UFMG. Impresso), v. 32, n. 4, p. 175-204, out./dez. 2016.

SOUSA, Andréia da Silva Quintanilha; MÁRTIRES, Hugo; SOUSA, Carolina. Motivos para evadir da Escola Superior de Educação e Comunicação da Universidade do Algarve/Portugal, segundo os estudantes. Revista Educação Em Questão, v. 56, n. 47, p. 42-68, 2018. https://doi.org/10.21680/1981-1802.2018v56n47ID13998

TASSONI, Elvira C. M. As experiências de sucesso na aprendizagem e suas relações com a permanência na escola. Revista de Educação PUC-Campinas, Campinas, v. 16, n. 1, p. 57-64, jan./jun. 2011.

TINTO, Vicent. Research and practice of student retention: what next? Journal of College Student Retention, v. 8, n. 1, p. 1-19, 2007. 
UNIVERSIDADE FEDERAL DO RIO GRANDE DO NORTE (UFRN). Proposta pedagógica para curso de graduação licenciatura em Pedagogia na modalidade à distância. 2010. Disponível em:

http://www.sedis.ufrn.br/images/documentos/pedagogia/PPP_PEDAGOGIA_A_DISTAN CIA.pdf. Acesso em: 21 jun. 2018.

VYGOTSKY, Lev S. A formação social da mente. São Paulo: Martins Fontes, 2007.

Recebido em: 30/01/2020

Aprovado: 26/03/2020 